\title{
Pyo-mediastinitis: A complication of pulmonary coccidioidomycosis
}

\author{
Mohamed Y Rady MD PhD FCCM, Arturo Lopez MD, Bhavesh M Patel MD, Joel S Larson MD
}

MY Rady, A Lopez, BM Patel, JS Larson. Pyo-mediastinitis: A complication of pulmonary coccidioidomycosis. C an J Infect $D$ is $2003 ; 14(3): 170-172$.

A rare fatal case of pulmonary coccidioidomycosis complicated by mediastinal and visceral abscesses treated with antifungal medications is described. The case report discusses the potential need for early surgical intervention to drain mediastinal and visceral abscesses as a primary mode of therapy in disseminated coccidioidomycosis for a successful control of infection and clinical outcome.

Key Words: Abscess; Coccidioidomycosis; Pyo-mediastinitis; Surgical drainage

\section{M édiastinite purulente: complication d'une coccidioïdomycose pulmonaire}

Voici un cas rare de coccidioïdomycose pulmonaire mortelle, compliquée d'abcès viscéraux et médiastinaux, qui a été traité aux antifongiques. II sera question, dans le présent exposé de cas, de la pertinence de l'intervention chirurgicale précoce pour drainer les abcès viscéraux et médiastinaux, et ce comme principale forme de traitement dans les cas de coccidioïdomycose disséminée, afin de juguler l'infection et d'obtenir de bons résultats cliniques.
C occidioidomycosis is an infection caused by the soilinhabiting fungus Coccidioides immitis. The fungus is endemic in the Southwest desert including A rizona (1). Coccidioidomycosis is normally a self-limited infection in healthy hosts presenting as a mild flu-like illness in approximately $40 \%$ of infected persons and progressing to severe pulmonary or disseminated disease in $1 \%$ to $10 \%$ of symptomatic cases (2). The early diagnosis of coccidioidomycosis infection relies on clinical suspicion and serological testing because direct tissue culture or histopathology may be delayed or difficult. We describe a rare fatal case of pulmonary coccidioidomycosis complicated by multiple mediastinal and visceral abscesses.

\section{CASE PRESENTATION}

A 78-year-old white woman was admitted to the intensive care unit with acute respiratory distress syndrome secondary to community acquired pneumonia for mechanical ventilation. Patient was an active smoker of 50-pack-year history and has lived in A rizona for the past four years. The patient was receiving hydroxyurea $500 \mathrm{mg}$ twice daily for Philadel phia chromosome negative chronic myelogenous leukemia diagnosed on bone marrow biopsy four months previously and was discontinued on admission to the intensive care unit. The patient had received radioactive iodine, I-131, for $\mathrm{G}$ rave's hyperthyroidism one year before. There was no history of diabetes mellitus, liver disease or prior treatment with corticosteroids. M ediastinal lymphadenopathy was noted on a surveillance computerized tomography of the thorax six months earlier (Figure 1A). A repeat thoracic and abdominal computerized tomography on admission to the intensive care unit showed right middle lobe pulmonary cavity lesion (Figure 1B, left) and multiple enlarged mediastinal lymph nodes with central necrosis and abscess formation (Figure 1B, right), and smaller military abscesses in both the liver and spleen. A fter initiation of mechanical ventilation bronchoscopic bronchoalveolar lavage was performed, which indicated on staining the presence of rare Gram-negative bacillus bacteria without additional speciation. Broad antibiotic coverage for $\mathrm{G}$ ram-negative bacteria was started on admission to intensive care unit. A ntifungal treatment with intravenous fluconazole at $400 \mathrm{mg}$ daily was initiated on day one after admission to the intensive care unit, when coccidioidomycosis diagnosis was confirmed serologically. C immitis serology confirmed the presence of both Immunoglobulin (Ig) $G$ and IgM antibodies to the fungal species indicating a primary pulmonary coccidioidomycosis infection. 0 n day 5 , bronchoalveolar lavage fluid grew only $C$ immitis. $O \mathrm{n}$ the same day, the patient developed septic shock and concurrent blood cultures grew only $\mathrm{C}$ immitis. At that time, fluconazole therapy was converted to a continuous intravenous infusion of amphotericin B (at $1 \mathrm{mg} / \mathrm{kg}$ every $24 \mathrm{~h}$ ) in addition to broad antibiotic coverage for $\mathrm{G}$ ram-negative bacteria. Surgical consultation was requested for operative drainage of mediastinal and abdominal abscesses. The family declined surgical intervention, and the patient subsequently died from multiple organs

D epartment of $C$ ritical $C$ are $M$ edicine, $M$ ayo $C$ linic $H$ ospital, $M$ ayo $C$ linic Scottsdale, Phoenix, A rizona, U SA

C orrespondence: Dr M ohamed Y Rady, D epartment of C ritical C are M edicine, M ayo C linic H ospital, 5777 East M ayo Boulevard, Phoenix,

A rizona 85054 U SA . Telephone 480-342-1387, fax 480-342-1388, e-mail rady. mohamed@mayo.edu

Received for publication December 16, 2002. A ccepted for publication F ebruary 22, 2003 

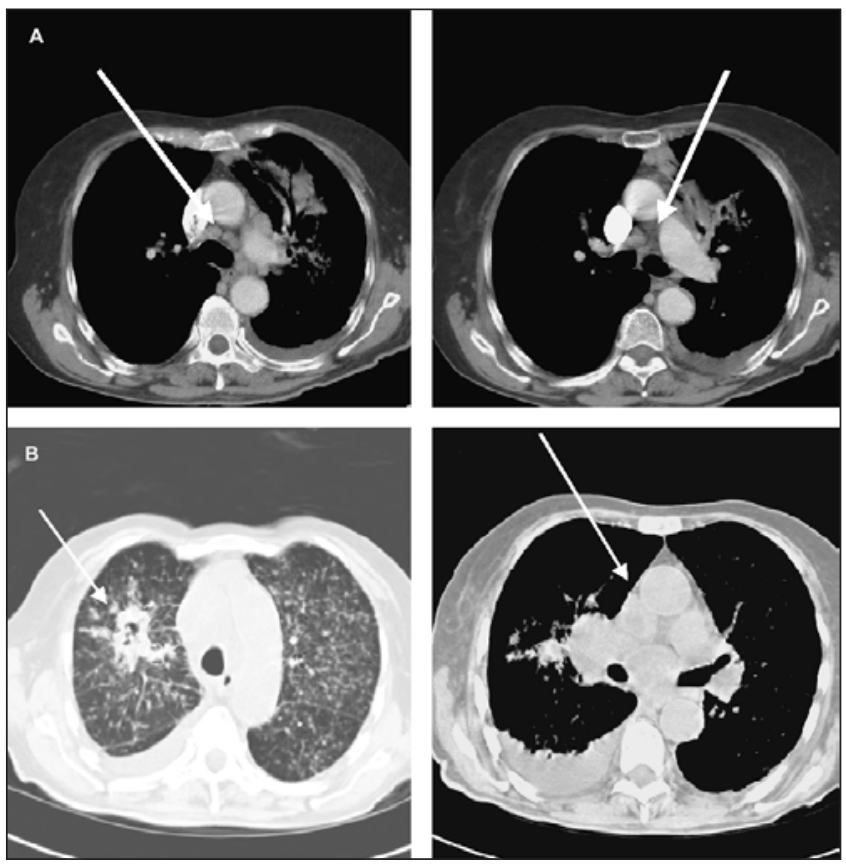

Figure 1) Computerized tomography of the thorax: A (left and right) Small mediastinal lymphadenopathy six months earlier; B (left and right) Right middle lobe cavity nodule, bilateral diffuse interstitial nodularity (left) and mediastinal Iymphadenopathy with central liquefaction necrosis (right) associated with pulmonary coccidioidomycosis on admission to intensive care unit

dysfunction syndrome while receiving antifungal therapy on day 17 of her intensive care unit stay. A utopsy confirmed multiple enlarged mediastinal lymph nodes with central necrosis and liquefied pus (Figure 2a). Histopathological examination of the abscesses confirmed the presence of spherules of $\mathrm{C}$ immitis (Figure 2b). Pus and tissue cultures obtained at autopsy from abscesses found in the spleen and liver grew only $\mathrm{C}$ immitis. A $n$ autopsy examination of the central nervous system was not performed.

\section{DISCUSSION}

The underlying immune suppression from hematological malignancy and cytotoxic chemotherapy, as well as heavy smoking history, were undoubtedly risk factors for systemic dissemination of $C$ immitis in this case report (3). Patients considered at high risk for systemic dissemination and increased mortality from $\mathrm{C}$ immitis have advanced age, congestive heart failure, cancer, diabetes mellitus, heavy smoking history, chronic corticosteroids use, A fro-A merican race and pregnancy $(4,5)$.

Systemic coccidioidomycosis can present as acute sepsis, particularly in an immunocompromised host or in high risk patients residing in an endemic area $(6,7)$. M edical treatment of systemic coccidioidomycosis focuses on early initiation of parenteral antifungal medications with either azole agents (eg fluconazole, itracanazole, or ketoconazole) or amphotericin B, as well as hemodynamic and organ support of the critically ill (8-10). In this case, clinical deterioration to septic shock and multiple organ dysfunction ensued in spite of medical treatment generally recommended for systemic coccidioidomycosis
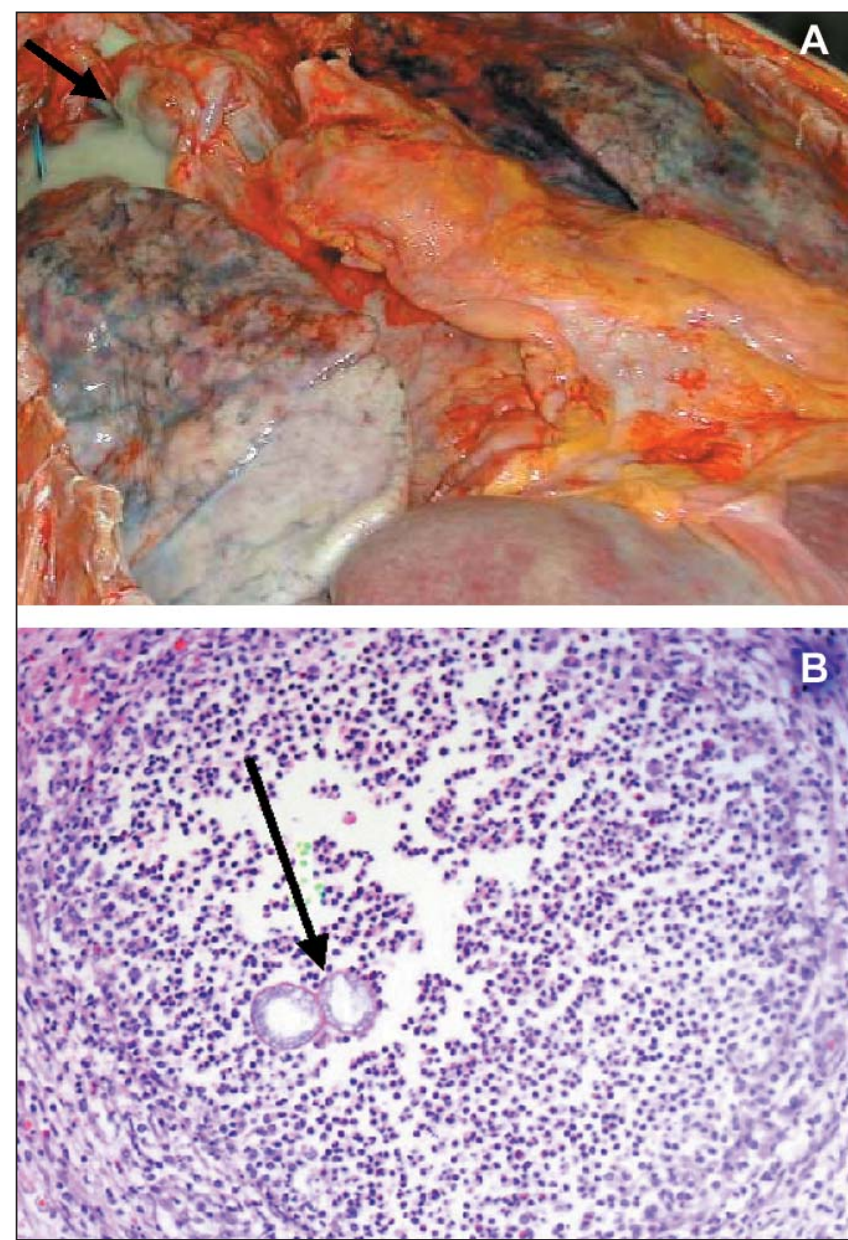

Figure 2 ) A utopsy pictures: A 0 pen thorax with purulent discharge from mediastinal lymph nodes and pyo-mediastinitis associated with pulmonary coccidioidomycosis. B A histopathological microscopic examination of one of the abscesses showing the presence of two spherules of $C$ occidioides immitis ( 0 riginal magnification $\times 200$ )

$(5,9,10)$. Large mediastinal abscesses formed within necrotic lymph nodes were refractory to antifungal medications as confirmed by repeated growth of $\mathrm{C}$ immitis from blood and tissue cultures. There are no reported cases or studies in the literature on either the incidence of mediastinal abscesses or the optimal surgical intervention necessary to treat such a complication when associated with pulmonary coccidioidomycosis. 0 perative intervention has been selectively reserved for visceral coccidioidomycosis resistant to antifungal therapy (11-14). Percutaneous drainage of hepatic abscesses, cholecystectomy or splenectomy has been described for the involvement of these organs. Mediastinal surgical drainage is frequently performed to relieve pericardial or airway compression in chronic granulomatous infections. However, the extent of surgical intervention required for purulent necrotic mediastinal nodes associated with coccidioidomycosis has not been described. Early timing of adjunct surgical intervention can improve the treatment response to antifungal agents for extrapulmonary coccidioidomycosis infection (12-14). O thers have recommended an initial trial of medical treatment with intravenous and/or enteral antifungal agents for a period of time before surgical intervention $(3,11,15)$. The latter recommendation will delay 
surgical treatment of visceral coccidioidomycosis and inevitably worsen clinical outcome in high risk patients as illustrated by this case report $(5,6,13)$. It may also be argued that surgical intervention in this particular case may not have altered the final outcome because of advanced presentation with mediastinal abscesses and concurrent visceral involvement. However, early diagnosis and timing of surgical intervention with effective medical therapy is the key to successful treatment of coccidioidomycosis.

Prevention of severe pulmonary disease and systemic dissemination has been proposed in high risk patients residing in endemic areas $(4,5)$. Early treatment with oral antifungal azole agents and perhaps vaccination against $C$ immitis promise to decrease future incidence of severe complications associated with extrapulmonary coccidioidomycosis (16).

\section{REFEREN CES}

1. A mpel N M, M osley DG, England B, Vertz PD, Komatsu K, $\mathrm{H}$ ajjeh RA . Coccidioidomycosis in A rizona: increase in incidence from 1990 to 1995. Clin Infect Dis 1998:27:1528-30.

2. Louie L, Ng S, Hajjeh R, et al. Influence of host genetics on the severity of coccidioidomycosis. Emerg Infect Dis 1999;5:672-80.

3. A rsura EL, Kilgore W B. Miliary coccidioidomycosis in the immunocompetent. Chest 2000;117:404-9.

4. Leake JA, M osley DG, England B, et al. Risk factors for acute symptomatic coccidioidomycosis among elderly persons in A rizona, 1996-1997. J Infect Dis 2000;181:1435-40.

5. Rosenstein N E, Emery KW, W erner SB, et al. Risk factors for severe pulmonary and disseminated coccidioidomycosis: Kern County, California, 1995-1996. Clin Infect Dis 2001;32:708-15.

6. A rsura EL, Bellinghausen PL, Kilgore W B, A braham JJ, Johnson RH . Septic shock in coccidioidomycosis. C rit $C$ are M ed 1998;26:62-5.

7. Cha JM, Jung S, Bahng HS, et al. M ulti-organ failure caused by reactivated coccidioidomycosis without dissemination in a patient with renal transplantation. Respirology 2000;5:87-90.

8. Goldman M, Johnson PC, Sarosi GA. Fungal pneumonias. The endemic mycoses. Clin Chest M ed 1999;20:507-19.

9. Galgiani JN, Catanzaro A, C loud G A, et al. Comparison of oral fluconazole and itraconazole for progressive, nonmeningeal

\section{ONCLUSIONS}

This fatal case of pulmonary coccidioidomycosis is unique because of early and rapid development of mediastinal and visceral coccidioidomycosis abscesses. Early detection of mediastinal and visceral coccidioidomycosis abscesses should prompt early surgical intervention for drainage as a primary mode of therapy in addition to effective antifungal therapy. Delay of surgical intervention is likely to result in multiple organ involvement and translates into poor prognosis.

Declaration of financial interests: The authors have no affiliations or financial involvement with any organization or entity with a direct financial interest in the subject matter or materials discussed in the manuscript.

coccidioidomycosis. A randomized, double-blind trial. M ycoses Study G roup. A nn Inter M ed 2000;133:676-86.

10. Deresinski SC. Coccidioidomycosis: efficacy of new agents and future prospects. Curr O pin Infect Dis 2001;14:693-6.

11. Sydorak RM, A Ibanese CT, Chen Y, W eintraub P, Farmer D. Coccidioides immitis in the gallbladder and biliary tree. J Pediatr Surg 2001;36:1054-6.

12. Connelly M B, Zerella JT. Surgical management of coccidioidomycosis in children. J Pediatr Surg 2000;35:1633-4.

13. Galgiani JN, A mpel N M , Catanzaro A, Johnson RH, Stevens DA, W illiams PL. Practice guideline for the treatment of coccidioidomycosis. Infectious Diseases Society of A merica. Clin Infect Dis 2000;30:658-61.

14. Thomas S, Basu S, Dutta R, C hibeer P, A ndley M, Kumar A. Coccidioidomycosis presenting as liver abscess. Indian J G astroenterol 2001;20:113-4.

15. Koehler A P, Cheng A F, Chu KC, Chan $\mathrm{CH}, \mathrm{H}$ o A S, Lyon DJ Successful treatment of disseminated coccidioidomycosis with amphotericin B lipid complex. J Infect 1998;36:113-5.

16. A buodeh RO, Shubitz LF, Siegel E, et al. Resistance to C occidioides immitis in mice after immunization with recombinant protein or a DN A vaccine of a proline-rich antigen. Infect Immun 1999;67:2935-40. 


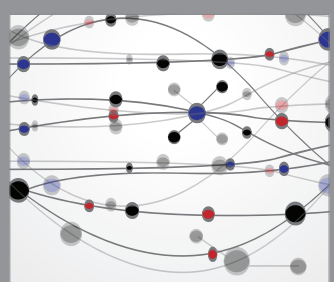

The Scientific World Journal
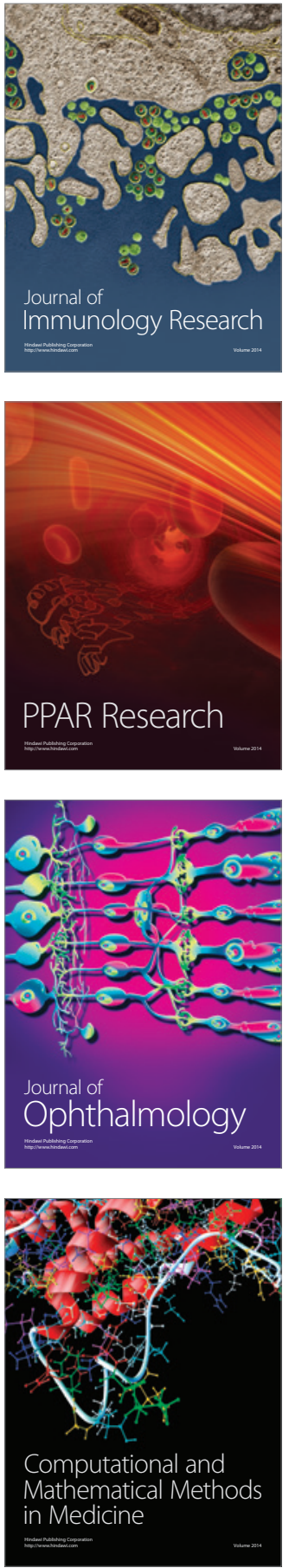

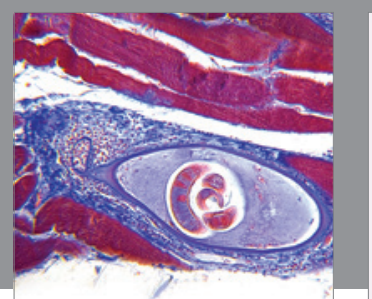

Gastroenterology Research and Practice

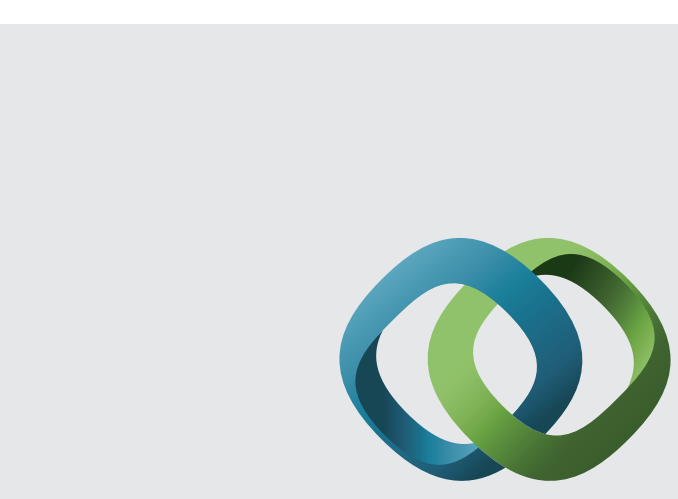

\section{Hindawi}

Submit your manuscripts at

http://www.hindawi.com
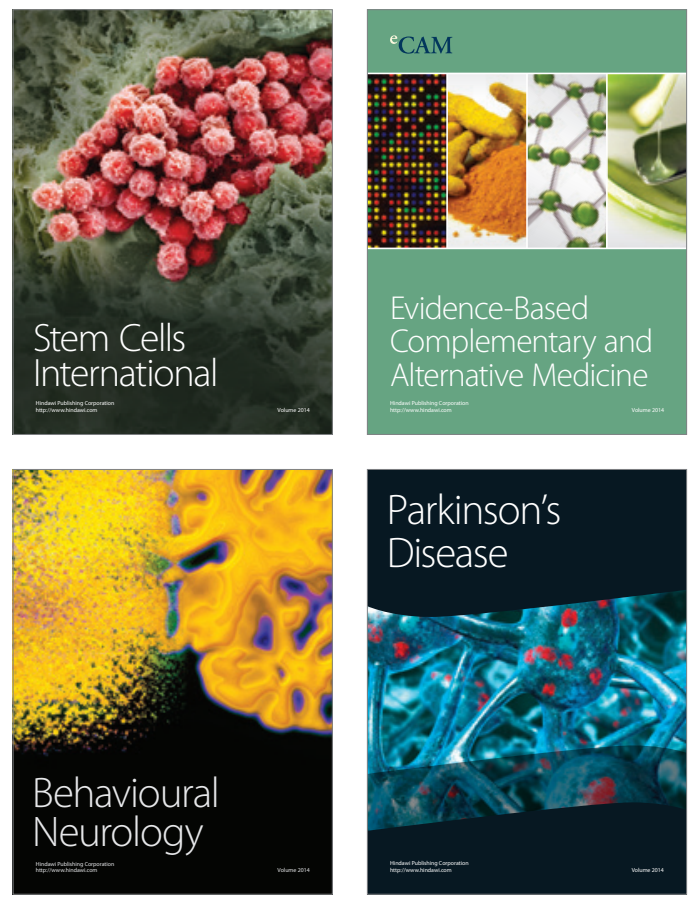
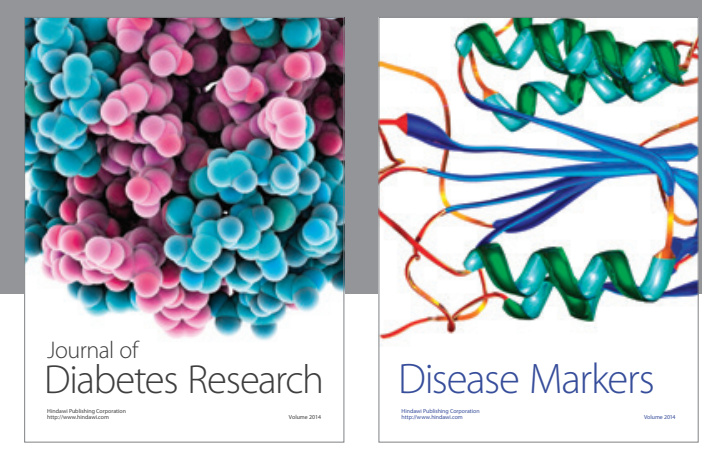

Disease Markers
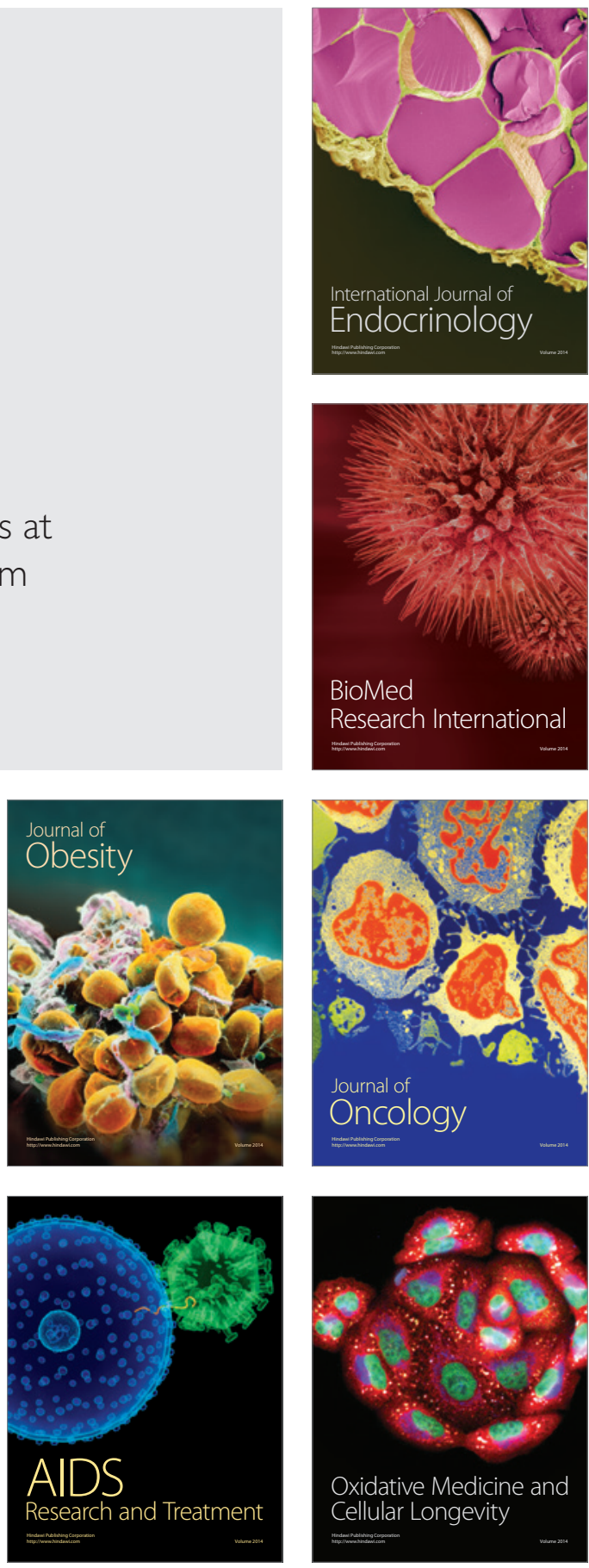